\title{
Türkiye Genelinde Prematüre Tanı-Tedavi Merkezlerinin ve Bu Merkezlerde Çalışan Uzman Göz Doktorlarının Çalışma Koşulları ve Tedavi Tercihleri
}

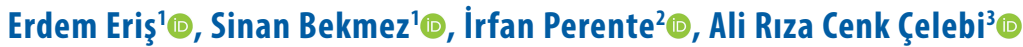

'Sağlık Bilimleri Üniversitesi İzmir Dr. Behçet Uz Çocuk Hastalıkları ve Cerrahisi Eğitim ve Araştırma Hastanesi, Göz Hastalıkları Bilim Dalı, İzmir, Türkiye

${ }^{2}$ Sağlık Bilimleri Üniversitesi İstanbul Beyoğlu Göz Eğitim ve Araştırma Hastanesi, Göz Hastalıkları Bilim Dalı, İstanbul, Türkiye

${ }^{3}$ Acıbadem Üniversitesi Tıp Fakültesi, Göz Hastalıkları Bilim Dalı, İstanbul, Türkiye

Erdem Eriş, Doç. Dr.

Sinan Bekmez, Uzm. Dr.

İrfan Perente, Prof. Dr.

Ali Rıza Cenk Celebi, Doç. Dr.

İletişim:

Doç. Dr. Erdem Eriş

Sağlık Bilimleri Üniversitesi İzmir Dr. Behçet Uz Çocuk Hastalıkları ve Cerrahisi Eğitim ve Araştırma Hastanesi, Göz Hastalıkları Bilim Dalı, İzmir, Türkiye

Tel: +905054006254

E-Posta: erdem-eris@hotmail.com

Gönderilme Tarihi : 25 Nisan 2019

Revizyon Tarihi : 25 Temmuz 2019

Kabul Tarihi

: 26 Temmuz 2019
ÖZET

Amaç: Türkiye genelinde prematüre tanı ve tedavi merkezlerinin öncelikli tedavi tercihlerini ve çalışma koşullarını değerlendirmek.

Gereç ve Yöntem: En az bir yıl prematüre (PR) tanı ve tedavi merkezlerinde çalışmış göz uzmanlarına çalışmaya katı Imaları için davet yollandı. Kabul eden uzmanlar çalışmaya dâhil edildi. Çalışmaya katılanlar online olarak Google anketler üstünden değerlendirilmeye alındı.

Bulgular: PR tanı ve tedavi merkezinde çalışan 26 göz uzmanı çalışmaya katıllı. Çalışma koşullarından uzmanların $\% 46,2$ si orta seviyede memnunken $\% 11,5^{\prime} \mathrm{i}$ hiç memnun olmadığı görüldü. PR muayenesi merkezlerin $\% 84,6^{\prime}$ sında diğer hastalardan ayrı bir yerde yapıldığı görüldü. Tanı ve tedavi merkezlerinde en sık bulunan görüntüleme cihazı olarak kameralı indirekt oftalmoskop olduğu görüldü. Agresif posterior prematüre retinopatiler (APROP) dışındaki prematüre retinopatilerin tedavilerinde uzmanların öncelikli tercihlerinin lazer fotokoagülasyon olduğu görüldü.

Sonuç: PR tanı ve tedavi merkezlerinin olanakları, verilen destekler ve çalışan personelin memnuniyetleri bölgelere göre belirgin değişiklikler gösterebilmektedir.

Anahtar sözcükler: Premature, Premature retinopati, ROP, AP-ROP, Google anketler, Türkiye

STATUS OF THE PREMATURITY OF RETINOPATHY DIAGNOSIS-TREATMENT CENTERS AND ATTITUDES OF OPHTHALMOLOGISTS IN TURKEY

\section{ABSTRACT}

Objective: To aassess the working conditions and treatment preferences of premature retinopathy diagnosis and treatment centers across Turkey.

Material and Method: An invitation was sent to eye experts who worked at diagnosis and treatment centers of retinopathy of prematurity (ROP) at least for a year. Experts who accepted the invitation are included in the study. Data were collected online using Google surveys.

Results: Twenty-six eye specialists who worked in ROP diagnosis and treatment centers were the participants. While $46.2 \%$ of the eye experts stated an intermediate level of satisfaction regarding the working conditions, $11.5 \%$ reported as not satisfied at all. In $84.6 \%$ of the centers, the ROP examination was reported to be performed in a separate place from the other patients. Indirect ophthalmoscope with a camera was reported to be the most common imaging device in the diagnosis and treatment centers. Laser photocoagulation was the primary preference of the experts in the treatment of ROP except for the cases of aggressive posterior retinopathy (AP-ROP).

Conclusion: The resources of the PR diagnosis and treatment centers, the support provided and the satisfaction levels of the staff can show significant changes between regions.

Keywords: Prematurity, Retinopathy of Prematurity, ROP, AP-ROP, Google surveys, Turkey 
rematüre retinopatisi (PR) çocukluk çağı körlüklerinin en önemli sebeplerinden biridir (1). PR tanısında tedavi kararı verebilmek için düzenli takip gereklidir. Bunun için de bir çalışma ekibi, görüntüleme ve arşiv sistemi gerekmektedir. Dünya genelinde PR tanı ve tedavisi ile ilgilenenlerde son 12 yılda belirgin bir azalma olduğu bildirilmektedir (2). Türkiye'nin birçok bölgesinde PR tanı ve tedavi merkezi olmasına rağmen bu merkezlerin açılması için bir standart bulunmamaktadır. Bu nedenle, Türkiye'de PR tanı ve tedavi merkezlerinde gerek çalışan personel gerekse uygulanan tanı ve tedavi yöntemleri bakımından farklılıklar görülebilmektedir. Bu çalışmayı yapma amacımız bölgelere göre göz uzmanlarının tercih ettiği tedavi rejimlerini ve PR tanı ve tedavi merkezlerinin olanaklarını değerlendirmektir.

\section{Gereç ve Yöntem}

Çalışma Helsinki Deklerasyonu standartlarına uygun olacak şekilde Acıbadem Üniversitesi Etik Kurulu'ndan onay alınarak prospektif olarak yapıldı.

En az bir yıl PR tanı ve tedavi merkezlerinde çalışmış göz uzmanlarına çalışmaya katılmaları için davet yollandı. Kabul eden uzmanlar çalışmaya dâhil edildi. Çalışmaya katılan uzmanlardan, Google Anketler üzerinden hazırlanan ve kendilerine yollanan anketlerin doldurulması istendi. Tüm veriler Google Drive üzerinde şifreli olarak saklandı. Katılımcı uzmanlar, isimleri ve çalıştıkları hastaneler gizli tutularak Türkiye'nin bölgelerine göre gruplandırıldı.

Yapılan anketlerde; uzmanlara PR için öncelikli olarak tercih ettikleri tedavi, muayene ve tedavi işlemleri sırasında uzmanlara yardımcı olan personeller, kullandıkları görüntüleme cihazlarının marka ve modeli, uzmanların yöneticilerinden gördükleri destekten ve çalıştıkları ortamdan memnuniyet düzeyleri soruldu.

Göz hastalıkları uzmanlarının doldurduğu anketlerin demografik verilerini değerlendirmek için E-PICOS (New York) yazılımı kullanıldı.

Çalışmaya katılma davetine cevap vermeyenler ve PR tanı ve tedavi merkezinde bir yıldan az tecrübesi olan uzmanlar çalışma dışında bırakıldı.

\section{Bulgular}

Türkiye'nin çeşitli bölgelerinden PR konusunda uzman 26 göz doktoru çalışmaya katıldı. Çalışmaya 13 (\%50) PR konusunda tecrübeli uzman doktor (PR Uz. Dr.) Marmara Bölgesi'nden, yedi $(\% 26,9)$ PR Uz. Dr. Ege Bölgesi'nden, üç $(\% 11,5)$ PR Uz. Dr. İ̧ Anadolu Bölgesi'nden, bir $(\% 3,8)$ PR Uz. Dr. Akdeniz Bölgesi'nden, bir $(\% 3,8)$ Doğu Anadolu Bölgesi'nden, bir $(\% 3,8)$ PR Uz. Dr. Güneydoğu Anadolu Bölgesi'nden katıldı.

Tanı ve tedavi merkezlerinde en sık bulunan görüntüleme cihazı olarak kameralı indirek oftalmoskop olduğu görüldü (Şekil 1).

Agresif posterior prematüre retinopati'ler (APROP) dışındaki PR'lerin tedavilerinde uzmanların öncelikli tercihlerinin lazer fotokoagülasyon olduğu görüldü (Şekil 2).

Rop için kullandığınız görüntüleme cihazınız hangisi

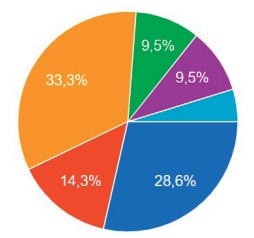

Retcam 2

Retcam 3

- Heine kameralt indirekt oftalmoskop

Panocam

- Keeler görüntüleme indir

oftalmoskop

Retcam 3 ve Heine kameralı indirekt

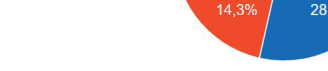

Şekil 1. Türkiye'de ROP merkezlerinde kullanılan görüntüleme cihazları.

ROP tedavisinde (APROP dışında) öncelikli seçeneğiniz nedir?

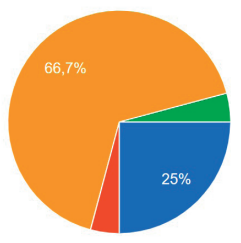

- Intravitreal anti-VEGF

Argon laze

- Diod lazer

Intravitrealle birlikte lazer kombine edavisi

Şekil 2. Türkiye'de AP-ROP dışındaki ROP tedavisinde tercih edilen ilk tedavi.

Tüm Türkiye'deki PR konusunda tecrübeli uzman doktorların memnuniyetleri; oldukça memnun, orta düzeyde memnun, kısmen memnun olanlar ve hiç memnun olmayanların oranları sırasıyla $\% 15,4, \% 46,2, \% 26,9$ ve $\% 11,5$ saptandı. Tüm Türkiye'deki PR konusunda tecrübeli uzman doktorlara, hastane yönetimleri tarafından verilen destekler; oldukça destek verenler, orta düzeyde destek verenler, kısmen destek verenler ve hiç destek vermeyenlerin oranları sırasıyla \%26,9, \%19,2, \%19,2 ve \%34,6 şeklindedir.

Marmara Bölgesi'ndeki PR konusunda tecrübeli uzman doktorların memnuniyetleri; oldukça memnun, orta düzeyde memnun, kısmen memnun olanların ve hiç memnun olmayanların oranları sırasıyla \%15,4, \%61,5, \%23,1 ve $\% 0$ saptandı. Marmara Bölgesi'ndeki PR konusunda 
tecrübeli uzman doktorlara yönetimleri tarafından verilen destekler; oldukça destek olanlar, orta düzeyde destek olanlar, kısmen destek olanların ve hiç destek olmayanların oranları sırasıyla $\% 38,5, \% 30,8,15,4$ ve 15,4 şeklindedir.

Ege Bölgesi'ndeki PR konusunda tecrübeli uzman doktorların memnuniyetleri; oldukça memnun, orta düzeyde memnun ve kısmen memnun olanların ve hiç memnun olmayanların oranları sırasıyla $\% 0, \% 43,9, \% 14,3$ ve $\% 43,9$ saptandı. Ege Bölgesi'ndeki PR konusunda tecrübeli uzman doktorlara yönetimleri tarafından verilen destekler; oldukça destek olanlar, orta düzeyde destek olanlar, kısmen destek olanlar ve hiç destek olmayanların oranları sırasıyla $\% 0, \% 0, \% 14,3$ ve $\% 85,7$ şeklinde saptandı.

İç Anadolu Bölgesi'ndeki PR konusunda tecrübeli uzman doktorların memnuniyetleri; oldukça memnun, orta düzeyde memnun, kısmen memnun olanlar ve hiç memnun olmayanların oranları sırasıyla $\% 66,7, \% 0, \% 33,3$ ve $\% 0$ olarak saptandı. İç Anadolu Bölgesi'ndeki PR konusunda tecrübeli uzman doktorlara yönetimleri tarafından verilen destekler; oldukça destek olanlar, orta düzeyde destek olanlar, kısmen destek olanlar ve hiç destek olmayanların oranları sırasıyla $\% 66,7, \% 0, \% 33,3$ ve $\% 0$ şeklindedir.

Akdeniz, Güneydoğu Anadolu ve Doğu Anadolu bölgelerindeki PR konusunda tecrübeli uzman doktorların memnuniyetleri sırasıyla "kısmen memnun, oldukça memnun ve kısmen memnun" olarak saptanmıştır. Akdeniz, Güneydoğu Anadolu ve Doğu Anadolu bölgelerindeki PR konusunda tecrübeli uzman doktorlara yönetimleri tarafından verilen destekler sırasıyla "kısmen destek olan, oldukça desten olan ve hiç destek olmayan" şeklindedir.

PR muayenesi yapılan yerler incelendiğinde $\% 84,6$ 'sında diğer hastalardan ayrı bir yerde, \%15,6'sında ise diğer hastalarla aynı odada PR muayenesi yapılmaktadır. Bölge değerlendirmesi yapıldığında PR muayenesi yapılan hastalar ile diğer hastaların aynı odada bakıldığı kliniklerin \%75'i Ege Bölgesi'nde, \%25'i Marmara Bölgesi'ndeydi; diğer bölgelerde ise PR muayenesi yapılan hastalar ile diğer hastalar ayrı odalarda bakılmaktaydı (Şekil 3).

\section{Tartışma}

Dünya genelinde, yenidoğanlara uygulanan gelişmiş tedaviler sonucunda erken prematürelerin yaşama olasılığının artmasıyla PR insidansında da belirgin artış beklenmektedir (3). Bu durum PR olan bebeklerin takibinde ve tedavisinde ciddi aksaklıklara neden olabilecektir (2). Dünya genelinde PR tanı ve takiplerinde teletıp görüntüleme

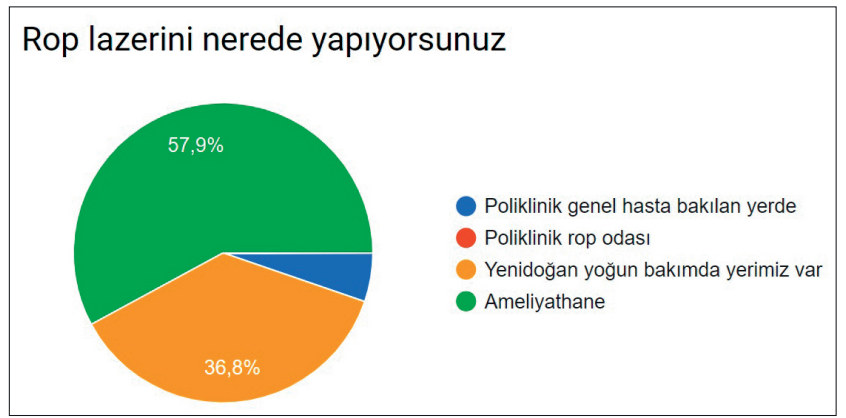

Şekil 3. Türkiye'de ROP lazeri hastanede nerede yapılmaktadır.

kullanımının yararlı oluğunu düşünen uzman sayısı, yararlı olduğunu düşünmeyenlerin sayısının iki katıdır (4). Fakat, PR muayenesi yapılması gereken bebek sayısının artması durumunda teletıp görüntülemesi bebeklerin tanı ve takibinde daha etkili bir yöntem haline gelebilir. Teletıp görüntüleme çalışmalarında oftalmologların yanı sıra kamera operatörlerinin de başarılı olduğu belirtilmektedir $(5,6)$. PR muayenesi yapılması gereken bebek sayısının, bu muayene ile ilgilenen uzman sayısına göre belirgin düzeyde artması durumunda, PR taramalarında oftalmologlar dışında kamera operatörlerinden de destek alınabilir.

Skleral depresyon ile yapılan indirekt oftalmoskop muayenesinin bebeklerde fiziksel stres oluşturduğu iyi bilinmektedir (7-12). Bununla birlikte, bazı uzmanlara göre RetCam-120 cihazı ile özellikle palpebral fissür aralığı dar olan bebeklerin periferik retinasını göstermenin zor olduğunu bildirilmektedir (13-15). Buna karşın RetCam ile farkIı merceklerle farklı açılarda görüntüler elde edilebileceği de bildirilmektedir (16). Çalışmamıza katılan uzmanların $\% 42,8$ 'i sadece indirekt oftalmoskopu, \%28,6'sı RetCam II'yi, \%9,5'i Panocam'i, \%14,3'ü RetCam III'ü kullanmaktadır.

Özellikle yenidoğan döneminde geçirilen bir göz enfeksiyonu sonucu oluşan korneal opasite, bebeklerde ambliyopi gibi ciddi ve tedavisi çok zor sonuçlara neden olabilir (17). Özellikle adenoviral keratokonjonktivit enfeksiyonu oldukça bulaşıcıdır ve korneal opasitelere neden olabilir $(18,19)$. Bu nedenle PR muayenelerinin ve tedavilerinin, diğer hastaların bakıldığı yerden ayrı bir muayene odasında uygulanmasının daha güvenli olacağını düşünmekteyiz. Bizim çalışmamızda Türkiye genelindeki merkezlerin $\% 15,6$ 'sında PR muayenelerinin, diğer hastalar ile aynı odada uygulanmakta olduğu, bunların da \%75'inin Ege Bölgesi'nde bulunduğu görülmektedir.

Adams ve ark., İngiltere'de PR nedeni ile tedavi edilen 327 hastayı incelemişler; bu çalışmada hastaların \%90,6'sının tedavisinde göz uzmanları ilk tercih olarak lazer 
fotokoagülasyon tedavisini seçerken, geri kalanının tedavisinde ise intravitreal anti-vasküler endotelyal büyüme faktörü (anti-VEBF) uygulamasını tercih ettiklerini bildirmişlerdir. Intravitreal anti-VEBF tedavisinin tercih edildiği hastaların da büyük çoğunluğunun agresif posterior PR olduğu bildirilmiş̧ir (20). Bizim çalışmamızda Tip I PR tedavisinde, PR konusunda tecrübeli uzman doktorların $\% 70,9^{\prime}$ u ilk tercih olarak lazer fotokoagülasyon tedavisini, $\% 25$ i intravitreal anti-VEBF'yi, \%4,2'si ise lazer + intravitreal anti-VEBF kombine tedavisini tercih etmektedir.

PR tedavisi için lazer fotokoagülasyon tedavisini tercih eden katılımcıların $\% 57,9^{\prime} u$ ameliyathanede, $\% 36,8^{\prime} i$ yenidoğan yoğun bakım ünitelerindeki PR tedavi odasında, \%5,3'ü poliklinikte genel hasta bakılan odada bu işlemi uygulamaktadır. İşlemin yapılacağı yer ile ilgili bir

\section{Kaynaklar}

1. Lad EM, Hernandez-Boussard T, Morton JM, Moshfeghi DM. Incidence of retinopathy of prematurity in the United States:1997 through 2005. Am J Ophthalmol 2009;148:451-8.e2. [CrossRef]

2. Vartanian RJ, Besirli CG, Barks JD, Andrews CA, Musch DC. Trends in the Screening and Treatment of Retinopathy of Prematurity. Pediatrics 2017;139:e20161978. [CrossRef]

3. Polin RA, Bateman D. Oxygen-saturation targets in preterm infants. N Engl J Med 2013;368:2141-2. [CrossRef]

4. Kemper AR, Wallace DK, Quinn GE. Systematic review of digital imaging screening strategies for retinopathy of prematurity. Pediatrics 2008;122:825-30. [CrossRef]

5. Chiang MF, Wang L, Busuioc M, Du YE, Chan P, Kane SA, et al. Telemedical retinopathy of prematurity diagnosis: accuracy, reliability, and image quality. Arch Ophthalmol 2007;125:1531-8. [CrossRef]

6. Scott KE, Kim DY, Wang L, Kane SA, Coki O, Starren J, et al. Telemedical diagnosis of retinopathy of prematurity intraphysician agreement between ophthalmoscopic examination and image-based interpretation. Ophthalmology 2008;115:1222-8.e3. [CrossRef]

7. Belda S, Pallas CR, De la Cruz J, Tejada P. Screening for retinopathy of prematurity: is it painful? Biol Neonate 2004;86:195-200. [CrossRef]

8. Kumar H, Nainiwal S, Singha U, Azad R, Paul VK. Stress induced by screening for retinopathy of prematurity. J Pediatr Ophthalmol Strabismus 2002;39:349-50. [CrossRef]

9. Laws $D E$, Morton $C$, Weindling M, Clark D. Systemic effects of screening for retinopathy of prematurity. $\mathrm{Br} J$ Ophthalmol 1996;80:425-8. [CrossRef]

10. Rush R, Rush S, Nicolau J, Chapman K, Naqvi M. Systemic manifestations in response to mydriasis and physical examination during screening for retinopathy of prematurity. Retina 2004;24:2425. [CrossRef]

11. Rush R, Rush S, Ighani F, Anderson B, Irwin M, Naqvi M. The effects of comfort care on the pain response in preterm infants undergoing screening for retinopathy of prematurity. Retina 2005;25:59-62. [CrossRef] standardizasyon olmamakla birlikte yapılan işlemin genel olarak cerrahi bir işlem olduğu kabul görmektedir.

Her bölgeden eşit sayıda uzman doktorun çalışmaya katılmamış olması çalışmanın bir kısıtlılığı olarak değerlendirilebilir. Bunun nedeni Türkiye'nin bölgelerinde eşit sayıda PR konusunda tecrübeli uzman doktorun görev yapmıyor olması olarak değerlendirmekteyiz. Bununla birlikte çaıışmanın prospektif bir çalışma olması ve Türkiye'nin tüm bölgelerini kapsamasını çalışmamızın artı yönleri olarak değerlendirebiliriz.

Sonuç olarak PR tanı ve tedavi merkezleri için, kullanılan PR tanı ve tedavi yöntemleri ve ayrıca PR ile ilgilenen uzman doktorların çalışma koşulları açısından Türkiye'nin tüm bölgelerini kapsayan ortak bir yaklaşım görülmemektedir.

12. Slevin M, Murphy JF, Daly L, O'Keefe M. Retinopathy of prematurity screening, stress related responses, the role of nesting. $\mathrm{Br} J$ Ophthalmol 1997;81:762-4. [CrossRef]

13. Chiang MF, Keenan JD, Starren J, Du YE, Schiff WM, Barile GR, et al. Accuracy and reliability of remote retinopathy of prematurity diagnosis. Arch Ophthalmol 2006;124:322-7. [CrossRef]

14. Roth DB, Morales D, Feuer WJ, Hess D, Johnson RA, Flynn JT. Screening for retinopathy of prematurity employing the retcam 120: sensitivity and specificity. Arch Ophthalmol 2001;119:26872. https://jamanetwork.com/journals/jamaophthalmology/ article-abstract/265424

15. Yen KG, Hess D, Burke B, Johnson RA, Feuer WJ, Flynn JT. Telephotoscreening to detect retinopathy of prematurity: preliminary study of the optimum time to employ digital fundus camera imaging to detect ROP. J AAPOS 2002;6:64-70. [CrossRef]

16. Richter GM, Williams SL, Starren J, Flynn JT, Chiang MF. Telemedicine for retinopathy of prematurity diagnosis: evaluation and challenges. Surv Ophthalmol 2009;54:671-85. [CrossRef]

17. Gu B, Son J, Kim M. Amblyopia and strabismus by monocular corneal opacity following suspected epidemic keratoconjunctivitis in infancy. Korean J Ophthalmol 2011;25:257-61. [CrossRef]

18. Chigbu DI, Labib BA. Pathogenesis and management of adenoviral keratoconjunctivitis. Infect Drug Resist 2018;11:981-93. [CrossRef]

19. Yamazaki ES, Ferraz CA, Hazarbassanov RM, Allemann N, Campos M. Phototherapeutic keratectomy for the treatment of corneal opacities after epidemic keratoconjunctivitis. Am J Ophthalmol 2011;151:35-43.e31. [CrossRef]

20. Adams GG, Bunce C, Xing W, Butler L, Long V, Reddy A, DahlmannNoor AH. Treatment trends for retinopathy of prematurity in the UK. active surveillance study of infants at risk. BMJ Open 2017;7:e013366. [CrossRef] 